\title{
Twenty-year trends in the prevalence of Down syndrome and other trisomies in Europe: impact of maternal age and prenatal screening
}

\author{
Maria Loane ${ }^{1}$, Joan K Morris ${ }^{2}$, Marie-Claude Addor ${ }^{3}$, Larraitz Arriola ${ }^{4}$, Judith Budd ${ }^{5}$, Berenice Doray ${ }^{6}$, \\ Ester Garne ${ }^{7}$, Miriam Gatt ${ }^{8}$, Martin Haeusler ${ }^{9}$, Babak Khoshnood ${ }^{10}$, Kari Klungsøyr Melve ${ }^{11}$, \\ Anna Latos-Bielenska ${ }^{12}$, Bob McDonnell ${ }^{13}$, Carmel Mullaney ${ }^{14}$, Mary O’Mahony ${ }^{15}$, \\ Annette Queißer-Wahrendorf ${ }^{16}$, Judith Rankin ${ }^{17}$, Anke Rissmann ${ }^{18}$, Catherine Rounding ${ }^{19}$, Joaquin Salvador ${ }^{20}$, \\ David Tucker ${ }^{21}$, Diana Wellesley ${ }^{22}$, Lyubov Yevtushok ${ }^{23}$ and Helen Dolk ${ }^{\star}, 1$
}

This study examines trends and geographical differences in total and live birth prevalence of trisomies 21,18 and 13 with regard to increasing maternal age and prenatal diagnosis in Europe. Twenty-one population-based EUROCAT registries covering 6.1 million births between 1990 and 2009 participated. Trisomy cases included live births, fetal deaths from 20 weeks gestational age and terminations of pregnancy for fetal anomaly. We present correction to 20 weeks gestational age (ie, correcting early terminations for the probability of fetal survival to 20 weeks) to allow for artefactual screening-related differences in total prevalence. Poisson regression was used. The proportion of births in the population to mothers aged $35+$ years in the participating registries increased from $13 \%$ in 1990 to $19 \%$ in 2009 . Total prevalence per 10000 births was 22.0 (95\% Cl 21.7-22.4) for trisomy 21, $5.0(95 \% \mathrm{Cl} 4.8-5.1)$ for trisomy 18 and 2.0 (95\% Cl 1.9-2.2) for trisomy 13; live birth prevalence was $11.2(95 \% \mathrm{Cl} 10.9-11.5)$ for trisomy $21,1.04(95 \% \mathrm{Cl} 0.96-1.12)$ for trisomy 18 and $0.48(95 \% \mathrm{Cl} 0.43-0.54)$ for trisomy 13 . There was an increase in total and total corrected prevalence of all three trisomies over time, mainly explained by increasing maternal age. Live birth prevalence remained stable over time. For trisomy 21 , there was a three-fold variation in live birth prevalence between countries. The rise in maternal age has led to an increase in the number of trisomy-affected pregnancies in Europe. Live birth prevalence has remained stable overall. Differences in prenatal screening and termination between countries lead to wide variation in live birth prevalence.

European Journal of Human Genetics (2013) 21, 27-33; doi:10.1038/ejhg.2012.94; published online 20 June 2012

Keywords: trisomy 21; trisomy 18; trisomy 13; trends; maternal age; prenatal screening

\section{INTRODUCTION}

In Europe, the average age of women giving birth has steadily increased since the late 1970s. ${ }^{1}$ In 2009, 1 million births in the European Union were born to mothers aged 35 years and older. ${ }^{2}$ As chromosome autosomal trisomies are more prevalent in children born to older mothers, ${ }^{3}$ the increase in the proportion of births to older mothers can be expected to result in an increasing number of affected pregnancies.

Studies of Down syndrome (trisomy 21, T21) have shown increasing trends in affected pregnancies in various parts of the world attributed to increasing maternal age. ${ }^{4-7}$ Prenatal screening and subsequent termination of pregnancy for fetal anomaly (TOPFA) counteract this effect with respect to observed trends in live birth (LB) prevalence, although this varies between countries depending on policy, provision and uptake of prenatal screening. ${ }^{8}$ Prenatal diagnosis during the first and second trimester also leads to the recognition and recording of trisomy cases that would otherwise have been lost as spontaneous abortions, and it has been suggested that this, as well as increasing maternal age, may explain some of the increase in overall numbers of trisomy cases diagnosed. ${ }^{9}$ Stillbirths and late fetal deaths (FD) with chromosomal anomalies are often not included in studies, and estimates made of in utero survival from study cohorts have not been validated with recent population data. The last evaluations of T21 LB trends in Europe included cases born in 1999/2000. ${ }^{10,11}$ Little information is available in Europe on trends of Patau syndrome (trisomy 13, T13) or Edward syndrome (trisomy 18, T18).

EUROCAT (European Surveillance of Congenital Anomalies) is a network of population-based registries established in 1979 to conduct

${ }^{1}$ Institute of Nursing Research, University of Ulster, Jordanstown, UK; ${ }^{2}$ Centre for Environmental and Preventive Medicine, Barts and the London School of Medicine and Dentistry, London, UK; ${ }^{3}$ Division of Medical Genetics, Lausanne, Switzerland; ${ }^{4}$ Subdirección de Salud Pública, San Sebastian, Spain; ${ }^{5}$ Service de Genetique Medicale, University of Leicester, Leicester, UK; ${ }^{6}$ Department of Health Sciences, Hopital de Hautepierre, Strasbourg, France; ${ }^{7}$ Paediatric Department, Hospital Lillebaelt, Kolding, Denmark; ${ }^{8}$ Department of Health Information and Research, Guardamangia, Malta; ${ }^{9}$ Styrian Malformation Registry, Medical University of Graz, Graz, Austria; 10INSERM U953, Paris, France; ${ }^{11}$ Medical Birth Registry of Norway, Bergen, Norway; ${ }^{12}$ Polish Registry of Congenital Malformations, Poznan, Poland; ${ }^{13}$ Health Service Executive, Dublin, Ireland; ${ }^{14}$ Health Service Executive, Kilkenny, Ireland; ${ }^{15}$ Health Service Executive, Cork, Ireland; ${ }^{16}$ Birth Registry Mainz Model, Children's Hospital, University Medical Center of the Johannes Gutenberg University Mainz, Germany; ${ }^{17}$ Institute of Health \& Society, Newcastle University, Newcastle, UK; ${ }^{18}$ Malformation Monitoring Centre Saxony-Anhalt, Medical Faculty Otto-von-Guericke University Magdeburg, Germany; ${ }^{19}$ National Perinatal Epidemiology Unit, University of Oxford, Oxford, UK; ${ }^{20}$ Agencia de Salut Pública de Barcelona, Barcelona, Spain; ${ }^{21}$ Public Health Wales, Swansea, UK; ${ }^{22}$ Faculty of Medicine, University of Southampton and Wessex Clinical Genetics Service, Southampton, UK; ${ }^{23}$ OMNI-Net for Children, Rivne, Ukraine

*Correspondence: Professor H Dolk, Institute of Nursing Research Faculty of Life \& Health Science University of Ulster, Jordanstown Shore Road, Room 12L23, Co Antrim, BT37 OQB, Northern Ireland, UK. Tel: +02890 368 540; Fax: 02890368 341; E-mail: h.dolk@ulster.ac.uk

Received 30 November 2011; revised 6 March 2012; accepted 12 April 2012; published online 20 June 2012 
epidemiological surveillance of congenital anomalies in Europe. In this paper, we examine trends in the total prevalence of T21, T18 and T13 in the period 1990 to 2009; examine whether these trends are explained by increasing maternal age or by earlier diagnosis during pregnancy or both; describe trends in LB prevalence; examine the extent of geographic differences within Europe in LB prevalence and its explanation in terms of the maternal age profile and termination rate; describe late FD rates; and assess differences between countries in the types of screening or diagnostic test that led to a diagnosis of $\mathrm{T} 21$.

\section{METHODS}

EUROCAT currently has 41 member registries in 20 countries covering $31 \%$ of all births in the European Union. ${ }^{12}$ Information on member registries and their methods of case ascertainment are available. ${ }^{13,14}$ Each registry sends an anonymised uniformly coded data set to EUROCAT Central Registry containing information on cases of congenital anomaly registered in the local population. Cases include LB, stillbirths and late FD from 20 weeks gestational age (GA), and TOPFA at any gestation. The standardised data set allows diagnosis of up to nine syndromes or malformations for each case coded according to the International Classification of Diseases with British Paediatric Association extension code (ICD9/BPA or ICD10/BPA).

The criteria for including registries in this study were maternal age recorded for $\geq 80 \%$ of all births in the registry population and $\geq 80 \%$ ascertainment of Down syndrome (DS) according to an adapted version of the DS Data Quality Indicator ${ }^{15}$ for 2005-2009. This DS Data Quality Indicator calculates the ratio of observed to expected DS for each registry based on maternal age profile, external standard maternal age-specific rates and fetal survival correction factors to 20 weeks GA (see Appendix). The final study population consisted of 21 registries in 12 countries covering 6.12 million births, 1990-2009. The DS Data Quality Indicator for all included registries and all years combined was $1.04 \%$.

Cases of T13 (ICD10 codes: Q914-Q917, ICD9 code: 7581) T18 (ICD10 codes: Q910-Q913, ICD9 code: 7582) and T21 (ICD10 codes: Q90, ICD9 code: 7580) born between 1990 and 2009 were extracted from the central database in August 2011. This study did not distinguish between trisomy, translocation and mosaic. Although most of the registries indicated that they consult or receive direct notification of all T21 cases from cytogenetic laboratories in their region, some registries identified potential problems beyond their control hence some cases may be missed. Barcelona (Spain) and East Midlands and South Yorkshire (UK) have notification from some but not all of the cytogenetic labs in their region. Wielkopolska (Poland) has complete information on LB cases, but TOPFA cases are missed as the registry does not register TOPFA. Norway receives cases through the medical birth notification form from delivery units and neonatal intensive care units and misses about $20 \%$ of cases. ${ }^{6}$ In Saxony Anhalt (Germany), Cork and Kerry (Ireland) and South East Ireland case finding was mainly via obstetric or pediatric records.

Maternal age was recorded for over $99 \%$ of the birth population between 1990 and 2009, range $98.4-100 \%$. Maternal age was not recorded for $1 \%$ of trisomy cases, and these cases were excluded from the study.

Information on the first screening (ultrasound, serum, combined screening) or diagnostic test (amniocentesis or chorionic villus sampling) indicating or leading to a diagnosis of T21 was restricted to the years 2005-2009, as 2005 was the first year this information was routinely recorded by EUROCAT.

\section{Statistical analysis}

Total prevalence was calculated as:

$$
\frac{\mathrm{LB}+\mathrm{FD}+\mathrm{TOPFA} \ldots \text { with } \ldots \text { trisomy }}{\text { total } \mathrm{LB}+\text { Stillbirths }} \times 10000
$$

LB prevalence per 10000 births was calculated as

$$
\frac{\mathrm{LB} \ldots \text { with } \ldots \text { trisomy }}{\text { totalLB }} \times 10000
$$

'Perinatal mortality' was defined as (FD + first-week death) with trisomy/ $\mathrm{LB}+\mathrm{FD}$ with trisomy.
The 'perinatal mortality' rate was calculated as:

$$
\frac{\mathrm{FD}+1 \text { stweekdeaths } \ldots \text { with } \ldots \text { trisomy }}{\text { totalLB }+ \text { Stillbirths }} \times 10000
$$

Weights representing the probability of fetal survival to 20 weeks GA were applied to each TOPFA case based on GA at TOPFA to correct for artefactual screening-related differences in total prevalence (Appendix).

Total corrected prevalence was calculated as:

$$
\frac{\mathrm{LB}+\mathrm{FD}+\text { TOPFA corrected to } 20 \text { weeks GA with trisomy }}{\text { totalLB }+ \text { Stillbirths }} \times 10000
$$

Statistical analysis was conducted using STATA version 9.0 (StataCorp LP, College Station, TX, USA). Maternal age was categorized into six age bands $(<20,20-24,25-29,30-34,35-39,40+$ years $)$ and entered as a categorical variable in all models. Year of birth was entered as both a categorical variable (1990-1994, 1995-1999, 2000-2004 and 2005-2009) and a continuous variable. A Poisson regression model was used to assess trends over time with year of birth entered as a linear term and to examine the effect of adjusting for country, maternal age and correction for fetal survival to 20 weeks GA on these trends. The Poisson model presented prevalence rate ratio (PRR) estimates and 95\% confidence intervals (CI) relative to the maternal age baseline group (mothers 25-29 years) or baseline country (Austria) or year of birth (1990). Austria was selected as the baseline country, as its maternal age distribution approximated the average maternal age distribution for all countries combined.

\section{RESULTS}

Trends over time in maternal age distribution among all births in registry population

The proportion of births to older mothers $(35+$ years) in EUROCAT registries increased steadily from $13 \%$ in 1990 to $19 \%$ in 2009 . The proportion of older mothers varied by country and increased in 2000-2009 compared with 1990-1999 in all countries except Malta and Poland (Table 1).

\section{Maternal age-specific rates}

Figure 1 shows the total corrected prevalence for each trisomy by six maternal age groups. The PRRs of T21, T18 and T13 in mothers $40+$ years compared with mothers aged 25-29 years were 17.3 (95\% CI 16.3-18.4), 18.9 (95\% CI 16.8-21.3) and 10.2 (95\% CI 8.3-12.4), respectively. The PRRs of T21, T18 and T13 in mothers 35-39 years compared with mothers aged 25-29 years were 5.5 (95\% CI 5.2-5.8), 4.4 (95\% CI 3.9-4.9) and 4.1 (95\% CI 3.4-4.8), respectively.

\section{Pregnancy outcome and perinatal mortality}

Pregnancy outcomes for each of the trisomies are shown in Table 2. TOPFA were more common for T18 (71\%) and T13 (71\%) than T21 $(47 \%)$ and these proportions varied greatly by country (Table 2). Approximately one-third of TOPFA for all three trisomies $(28 \%$ of $\mathrm{T} 21,34 \%$ of T18 and $38 \%$ of T13 cases) were at 20 weeks GA or later. A total of $2 \%$ of T21 LB cases died before 1 week of age, compared with $45 \%$ of T18 LB cases and $54 \%$ of T13 LB cases (data not shown). Perinatal mortality associated with T18 (58\%) and T13 (58\%) was almost 10 times the perinatal mortality associated with T21 (6\%). The perinatal mortality rate per 10000 births in the population was 0.7 for T21, 0.8 for T18 and 0.3 for T13.

There was a significant difference in the proportion of FD among births (LB and FD) for T21 cases by maternal age $(P<0.01)$. Younger mothers $(<20$ years) had double the proportion of FDs among T21 births compared with mothers in other age groups. The proportion of FDs among T18 and T13 cases did not differ significantly by maternal age. 
Table 1 The number of EUROCAT registries, proportion of birth population covered by EUROCAT in 2007, number of births and proportion of older mothers, per country, 1990-2009

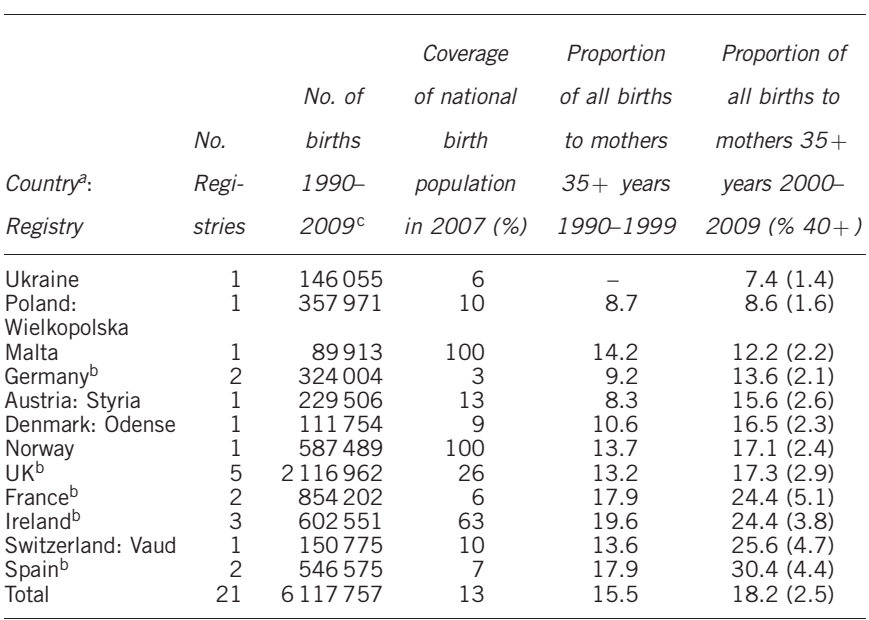

aCountries are ordered by \% mothers $35+$ years in 2000-2009.

bCountries with more than one EUROCAT registry: France (Paris, Strasbourg); Germany (Mainz Saxony Anhalt); Ireland (Cork and Kerry, Dublin, South East); Spain (Barcelona, Basque Country); UK (East Midlands and South Yorkshire, Northern England, Thames Valley, Wales, Wessex).

'Data covers 1990-2009 for all registries except: France Strasbourg 1990-2005; Germany Saxony Anhalt 1991-2009; Ireland, Cork and Kerry 1996-2005, 2008, South East 1997-2008; Norway 1999-2008; Poland 1999-2008; Spain, Barcelona 1992-2007, Basque Country 1990-2008; Ukraine 2005-2009; UK, East Midlands and South Yorkshire

1998-2009, Northern England 2000-2009, Thames Valley 1995-2009, Wales 1998-2009 and Wessex 1994-2009.

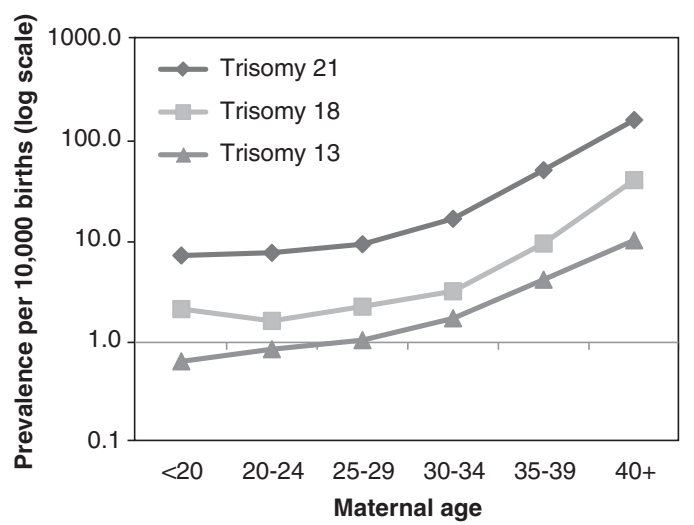

Figure 1 Total corrected prevalence per 10000 births (log scale) of trisomies 21,18 and 13 by maternal age, 1990-2009, 12 European countries.

Trend over time in total and LB prevalence of trisomies 21, 13, 18 Between 1990 and 2009, the total and LB prevalence of T21 was 22.0 (95\% CI 21.7-22.4) and 11.2 (95\% CI 10.9-11.5) per 10000 births. The total and LB prevalence of T18 was 5.0 (95\% CI 4.8-5.1) and 1.04 (95\% CI 0.96-1.12) per 10000 births. The total and LB prevalence of T13 was 2.0 (95\% CI 1.9-2.2) and 0.48 (95\% CI 0.43-0.54) per 10000 births. There was a significantly increasing trend in the unadjusted total prevalence of the three trisomies (Figure 2). The PRR in 2009 compared with 1990, adjusting for country of birth, are shown in Table 3. Correction for fetal survival of TOPFA to 20 weeks GA made little impact on these estimates (Table 3). Adjustment for increasing maternal age in the populations removed any evidence of increasing trend of T21, but there remained evidence of increasing trend in both T18 and T13 (Table 3).
The LB prevalence remained stable for all three trisomies compared with the baseline period (Figure 2).

\section{Geographical variation in total corrected prevalence and LB prevalence of Trisomy 21 from 2000 to 2009}

There was geographical variation in total corrected prevalence of T21 $(P<0.001)$, (Figure 3$)$. After adjusting for the maternal age distribution in the population, the PPR point estimates by country were close to 1 except in France and Switzerland; France had 37\% higher corrected rates of T21 (95\% CI 1.18-1.59) and Switzerland 27\% (95\% CI 1.06-1.53) compared with the baseline country (Austria). In 10 of the 12 countries, over half of T21 cases occurred in mothers $35+$ years.

There was a more than three-fold variation in LB prevalence of T21 between countries with Ireland and Malta (where TOPFA is illegal and thus not performed) having the highest LB prevalence (Figure 3).

Prenatal diagnosis and type of prenatal screening or diagnostic test first indicating or leading to T21 diagnosis, 2005-2009

Thirteen registries in nine countries provided information on time of diagnosis and first prenatal screening or diagnostic test for $98 \%$ of cases from 2005 to 2009 . Overall, 1598 cases (62\%) were prenatally diagnosed (PD), ranging from $9 \%$ to $21 \%$ in Ireland and the Ukraine to over $80 \%$ in France, Spain and Switzerland. In all, 52\% of T21 cases were $\mathrm{PD}$ in mothers $<35$ years and $70 \%$ were $\mathrm{PD}$ in mothers $35+$ years, which varied by country (Figure 4 ).

Of the PD cases, $14 \%$ were $\mathrm{LB}, 2 \%$ were $\mathrm{FD}$ and $83 \%$ were TOPFA. The proportion of PD T21 cases resulting in TOPFA was $\geq 80 \%$ in all counties where TOPFA is practiced except Ukraine, (range $58 \%$ in Ukraine to $97 \%$ in Spain).

Of the PD cases, T21 was first suspected following ultrasound examination in just under a third of cases (range from 7-9\% in Denmark and Ireland to $46 \%$ in France), (Figure 5). The ultrasound test was performed $<14$ weeks GA in $58 \%$ of these cases $(>58 \%$ in Denmark, France, Span, Switzerland and UK). In all, 16\% of cases were diagnosed following a first positive indication from serum/ combined screening, (range from $0 \%$ in Germany, Ireland, Spain and Ukraine to $49 \%$ in Switzerland and $60 \%$ in Denmark), (Figure 5). A total of $16 \%$ of cases were diagnosed by chorionic villus sampling/ amniocentesis not preceded by any screening test, ranging from the minority of cases in most countries, to $28 \%$ of PD cases in Austria, $43 \%$ of PD in Germany and 59\% of PD in Spain, (Figure 5). Overall, of the $16 \%$ of $\mathrm{PD}$ cases diagnosed by invasive tests not preceded by ultrasound or biochemical screening tests, $78 \%$ were performed in mothers $35+$ years, range from $67 \%$ in Ireland to $100 \%$ in Denmark and France.

\section{DISCUSSION}

The rise in average maternal age in Europe over time has brought with it an increase in the number of pregnancies affected by trisomies 21, 18 and 13. However, the increasingly widespread practice of prenatal screening and termination of pregnancy has, on average, counteracted the effect of maternal age and resulted in a relatively stable LB prevalence of the major trisomies since 1990 in the European population studied. This is consistent with other studies in many areas of the world reporting no increasing trends over time in LB prevalence of the major trisomies, ${ }^{16,17}$ whereas total prevalence has been increasing. $5,7,18$

There are significant and changing geographic inequalities in both total and LB prevalence of T21. The 2.7-fold variation in total prevalence between countries from 2000 to 2009 is mainly due to the 
Table 2 The total number of cases $^{\mathrm{a}}$ with trisomies 21,18 and 13 and the proportion by pregnancy outcome by country, 1990-2009

\begin{tabular}{|c|c|c|c|c|c|c|c|c|c|c|c|c|c|c|c|}
\hline \multirow[b]{2}{*}{ Country } & \multicolumn{5}{|c|}{ Trisomy 21} & \multicolumn{5}{|c|}{ Trisomy 18} & \multicolumn{5}{|c|}{ Trisomy 13} \\
\hline & $\begin{array}{c}\text { Total } \\
\text { cases (n) }\end{array}$ & $\begin{array}{l}\angle B \\
(\%)\end{array}$ & $\begin{array}{l}F D \\
(\%)\end{array}$ & $\begin{array}{c}\text { TOPFA } \\
\text { (\%) }\end{array}$ & $\begin{array}{l}\% F D \text { of } \\
L B+F D\end{array}$ & $\begin{array}{c}\text { Total } \\
\text { cases (n) }\end{array}$ & $\begin{array}{l}\angle B \\
(\%)\end{array}$ & $\begin{array}{l}F D \\
(\%)\end{array}$ & $\begin{array}{l}\text { TOPFA } \\
\text { (\%) }\end{array}$ & $\begin{array}{l}\% F D \text { of } \\
L B+F D\end{array}$ & $\begin{array}{c}\text { Total } \\
\text { cases (n) }\end{array}$ & $\begin{array}{l}\angle B \\
(\%)\end{array}$ & $\begin{array}{l}F D \\
(\%)\end{array}$ & $\begin{array}{c}\text { TOPFA } \\
\text { (\%) }\end{array}$ & $\begin{array}{l}\% F D \text { of } \\
L B+F D\end{array}$ \\
\hline Austria: Styria & 381 & 51.4 & 2.1 & 46.5 & 3.9 & 78 & 21.8 & 5.1 & 73.1 & 19.1 & 57 & 28.1 & 7.0 & 64.9 & 20.0 \\
\hline Denmark: Odense & 209 & 47.4 & 5.3 & 47.4 & 10.0 & 47 & 25.5 & 10.6 & 63.8 & 29.4 & 17 & 17.7 & 5.9 & 76.5 & 25.0 \\
\hline France & 2690 & 25.2 & 1.7 & 73.1 & 6.2 & 737 & 7.1 & 4.9 & 88.1 & 40.9 & 266 & 7.5 & 3.4 & 89.1 & 31.0 \\
\hline Germany & 559 & 50.5 & 2.9 & 46.7 & 5.4 & 107 & 18.7 & 11.2 & 69.4 & 37.5 & 50 & 16.0 & 10.0 & 74.0 & 38.5 \\
\hline Ireland & 1369 & 94.7 & 5.1 & 0.2 & 5.1 & 225 & 64.4 & 35.6 & 0 & 35.6 & 118 & 78.8 & 21.2 & 0 & 21.2 \\
\hline Malta & 166 & 99.4 & 0.6 & 0 & 0.6 & 28 & 96.4 & 3.6 & 0 & 3.6 & 4 & 100.0 & 0 & 0 & 0.0 \\
\hline Norway & 1043 & 70.2 & 1.7 & 28.1 & 2.4 & 235 & 33.2 & 8.9 & 57.9 & 21.2 & 102 & 33.3 & 2.9 & 63.7 & 8.1 \\
\hline $\begin{array}{l}\text { Poland: } \\
\text { Wielkopolska }\end{array}$ & 515 & 99.6 & 0.4 & 0 & 0.4 & 55 & 94.6 & 5.5 & 0 & 5.5 & 19 & 84.2 & 15.8 & 0 & 15.8 \\
\hline Spain & 1357 & 32.6 & 0.8 & 66.6 & 2.4 & 290 & 12.4 & 3.1 & 84.5 & 20.0 & 99 & 14.1 & 2.0 & 83.8 & 12.5 \\
\hline Switzerland: Vaud & 437 & 23.3 & 1.6 & 75.1 & 6.4 & 86 & 7.0 & 5.8 & 87.2 & 45.5 & 39 & 15.4 & 0 & 84.6 & 0.0 \\
\hline Ukraine & 195 & 86.7 & 1.5 & 11.8 & 1.7 & 10 & 40.0 & 0 & 60.0 & 0.0 & 10 & 40.0 & 10.0 & 50.0 & 20.0 \\
\hline UK & 4550 & 48.8 & 3.4 & 49.8 & 6.7 & 1135 & 16.0 & 7.8 & 76.1 & 32.8 & 466 & 16.3 & 4.1 & 79.6 & 20.0 \\
\hline Total & 13471 & 50.5 & 2.6 & 46.9 & 4.8 & 3033 & 20.8 & 8.7 & 70.5 & 29.6 & 1247 & 23.6 & 5.8 & 70.7 & 19.7 \\
\hline
\end{tabular}

Abbreviations: FD, fetal deaths from 20 weeks; LB, live birth; MA, maternal age; TOPFA, termination of pregnancy for fetal anomaly (TOPFA is not legal in Ireland and Malta; and not practised in Poland).

Total $=$ LB + FD + TOPFA

aStudy exclusions due to unknown MA: 154 cases of T21 (4 Austria, 9 France, 28 Germany, 6 Ireland, 2 Malta, 28 Poland, 21 Spain and 56 UK); 25 cases of T18 (1 France, 7 Germany,

2 Ireland, 1 Malta, 2 Poland, 5 Spain and 7 UK); 10 cases of T13 (2 France, 2 Germany, 1 Norway, 4 Spain and 1 UK).

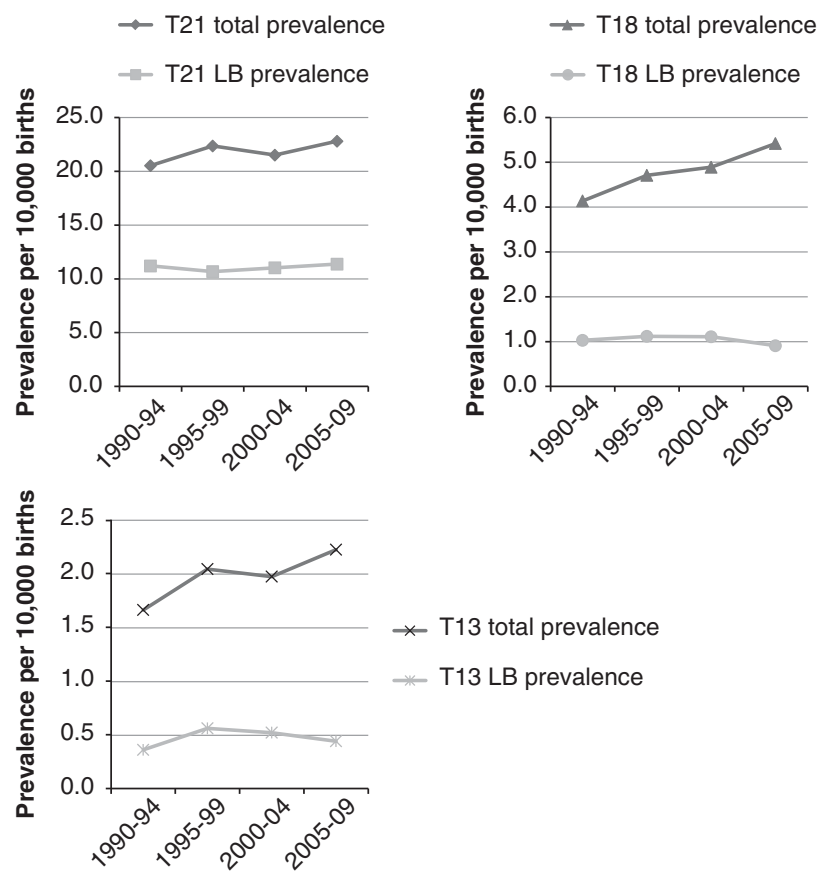

Figure 2 Total and LB prevalence per 10000 births of trisomy 21, 18 and 13 in 12 European countries, 1990-2009.

large variation in maternal age profile of European countries and regions within countries. Geographical variation in LB prevalence of T21 due to the differences in TOPFA rate between countries is even greater. There is a more than three-fold higher LB prevalence of T21 in countries where TOPFA is illegal (Ireland and Malta) ${ }^{8}$ than in other countries. Individual countries may also differ in their LB prevalence trends, and country-specific LB prevalence trends can be found on the EUROCAT website, updated each year. ${ }^{19}$

Because of the earlier detection of trisomies prenatally, more cases are now being diagnosed that would otherwise not have survived to birth. This is particularly true of trisomies 18 and 13, which have high natural early fetal loss rates. This problem has long been recognized for epidemiological surveillance, and standard correction factors have been employed for T21 to correct terminations of pregnancy for probability of survival to LB. $^{20,21}$ We instead corrected early terminations of pregnancy for probability of survival to 20 weeks GA, essentially calculating prevalence at 20 weeks GA in the absence of intervention. This meant we could compare total prevalence trends including all diagnosed cases to corrected total prevalence trends. We find however that such correction for fetal survival has little impact 
on total prevalence rates, especially for T21, and is certainly a much lesser explanation of temporal and geographic variation than maternal age.

An average late fetal loss rate of $25-30 \%$ for T21 is widely cited, ${ }^{20-23}$ which is much higher than the EUROCAT average late fetal loss rate of $5 \%$. Although some level of under ascertainment of late FD with T21 is possible in EUROCAT regions, especially for cases where there was no prenatal diagnosis, the close correspondence of EUROCAT rates to expected rates suggests high ascertainment. It is possible instead that prenatal diagnosis is selectively picking up T21 cases with serious heart or other structural anomalies with lower expected late fetal survival, thus depressing late FD proportions among those not PD. It is also possible that late miscarriage rates reported in the literature calculated from prenatal diagnosis series have selectively included pregnancies examined owing to signs of poor fetal growth, and/or that T21 babies born with severe heart anomalies were previously less likely to be registered as live births. EUROCAT late fetal loss rates for T18 and T13 are high and vary between European populations, but are also lower than estimates from prenatal diagnosis cohorts. ${ }^{17}$ Further research on late FD for trisomies is needed. Meanwhile, we recommend correcting total prevalence to 20 weeks GA instead of to LB, to avoid the assumption that late fetal loss for trisomies is constant across populations.

The perinatal mortality rate due to the three trisomies combined was 1.9 per 10000 births, of which nearly two-thirds was T18 and T13, which despite their low prevalence had high case fatality.

Table 3 The unadjusted and adjusted prevalence rate ratio (PRR) of each trisomy in 2009 relative to 1990, 12 European countries

\begin{tabular}{llll}
\hline & & $\begin{array}{l}\text { PRR adjusted } \\
\text { for country and } \\
\text { correction to } \\
\text { PRR adjusted } \\
\text { for country }\end{array}$ & $\begin{array}{l}\text { PRR adjusted } \\
\text { for country, MA } \\
\text { and correction } \\
\text { to } 20 \text { weeks GA }\end{array}$ \\
\hline Trisomy 21 & $1.48(1.38-1.58)$ & $1.46(1.36-1.56)$ & $1.00(0.93-1.07)$ \\
Trisomy 18 & $2.17(1.87-2.51)$ & $1.98(1.70-2.31)$ & $1.38(1.18-1.61)$ \\
Trisomy 13 & $1.80(1.43-2.26)$ & $1.69(1.34-2.14)$ & $1.26(1.00-1.60)$
\end{tabular}

Abbreviations: FD, fetal deaths from 20 weeks; LB, live birth; MA, maternal age; PRR, prevalence rate ratio.
We found evidence of some differences in total prevalence of the three trisomies over time and between countries that could not be completely explained by differing maternal age profiles or changes in GA at detection. There was evidence of an increasing trend in the adjusted total prevalence of T13 and T18 (but not T21) over time, which may relate to improvements in diagnosis (prenatal and/or postnatal) over time; and evidence that France and Switzerland had higher T21 total prevalence than others, requiring further investigation.

The EUROCAT total prevalence rates of T18 and T13 are broadly comparable with other studies, ${ }^{18,24-27}$ but exact comparison is difficult, as most studies concern LB rates and are from populations with different maternal age profiles.

Ultrasound and biochemical screening have been introduced on a population-wide basis in many European countries. There is no policy for prenatal screening of T21 in Ireland or Malta. ${ }^{28}$ Screening policy and uptake varies considerably ${ }^{8}$ as demonstrated in our data by both prenatal diagnosis rates and types of screening test performed. The distinction between ultrasound and combined screening in our data may be blurred as some ultrasounds might have been performed as part of an intended combined test but where the biochemical

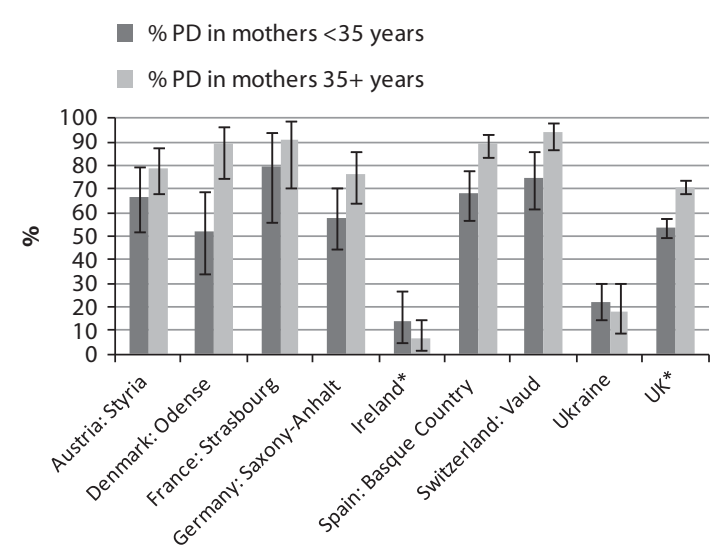

Figure 4 Proportion (with $95 \% \mathrm{Cl}$ ) of trisomy 21 cases prenatally diagnosed according to maternal age, 9 European countries.

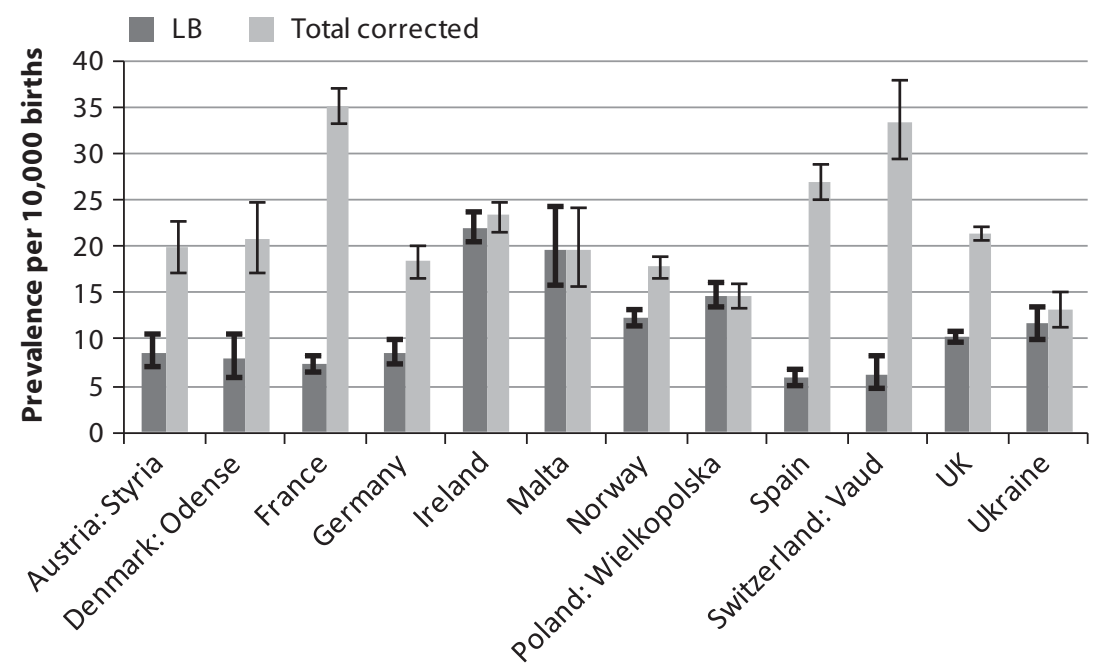

Figure 3 LB and total corrected prevalence (with 95\% Cl) per 10000 births of trisomy 21 in 2000-2009, 12 European countries (countries are ordered by $\%$ mothers $35+$ years in 2000-2009). Total corrected $=$ LB + FD + TOPFA corrected to 20 weeks GA. 


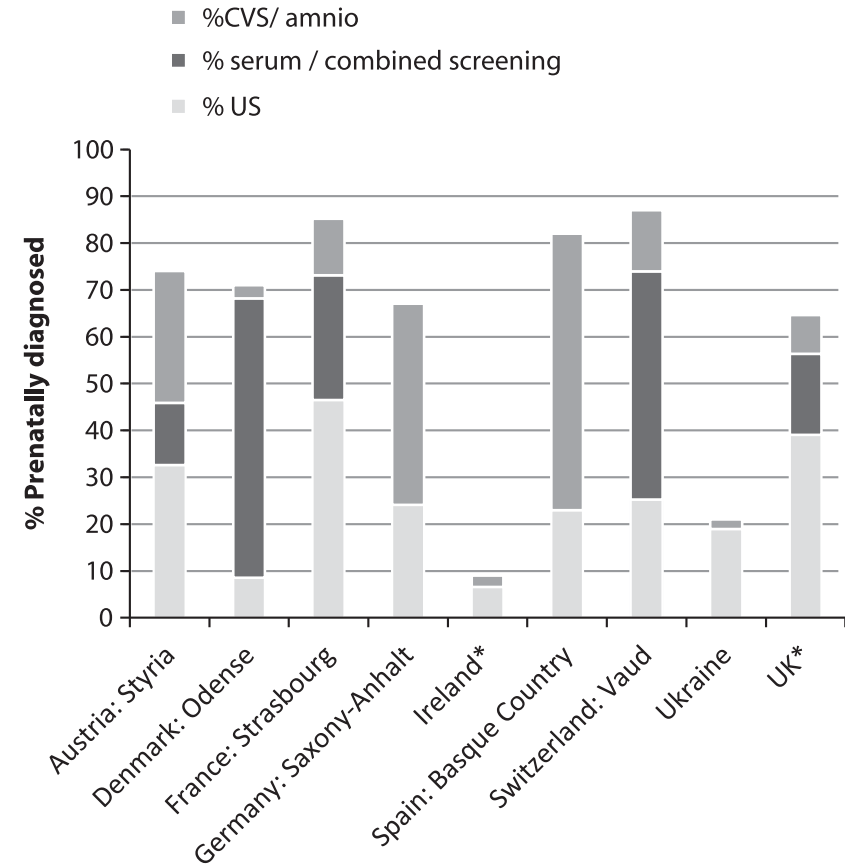

Figure 5 Proportion of trisomy 21 cases prenatally diagnosed by type of prenatal test first indicating or leading to prenatal diagnosis, 9 European countries, 2005-2009. US, Ultrasound CVS/ amnio, Chorionic villus sampling or amniocentesis. *Ireland (Cork and Kerry, South East Ireland), UK (Northern England, Thames Valley, Wales, Wessex).

screening was not carried out. According to our data, significant numbers of women in some countries are having an invasive test (amniocentesis or CVS) solely on indication of maternal age. Paradoxically, maternal age has increased over the years that screening methods have been developed to include younger maternal ages, and 10 of 12 countries report a majority of T21 cases among older mothers.

This study covers almost $13 \%$ of all births in the 12 European countries represented in 2007. The regions are representative of European statistics ${ }^{2}$ in terms of maternal age, especially since year 2000, but may differ in terms of prenatal screening and TOPFA from other regions in these countries. Some caution should therefore be exercised in interpretation of national differences. Continued surveillance of trisomy 13,18 and 21 is important for assessing the impact of delayed childbearing, evaluating screening programmes and providing health care. Prevalence of T21, T18 and T13 has increased over time, largely due to the increasing number of older mothers giving birth. However, owing to the increased use of prenatal screening and subsequent terminations, the LB prevalence of these trisomies has remained relatively constant.

\section{CONFLICT OF INTEREST}

The authors declare no conflict of interest.

\section{ACKNOWLEDGEMENTS}

This study was co-funded by the European Commission under the framework of the European Union Health Programme, Grant Agreement 2006103 (Executive Agency for Health and Consumers). EUROCAT registries are funded as fully described in Paper 6 of Report 9 - EUROCAT Member Registries: Organization and Activities. The responsibility for the interpretation of data and/or information supplied is the authors' alone. We thank the many people throughout Europe involved in providing and processing information, including affected families, clinicians, health professionals, medical record clerks and registry staff.

1 Breart G: Delayed childbearing. Eur J Obstet Gynecol Reprod Biol 1997; 75: 71-73.

2 EU statistics (EUROSTAT): maternal age at birth. http://epp.eurostat.ec.europa.eu/ portal/page/portal/population/data/database (accessed 5 August 2010).

3 Smith DW: Recognizable patterns of human malformation, 3rd edn Philadelphia: WB Saunders Company, 1992

4 Khoshnood B, De Vigan C, Vodovar V, Goujard J, Goffinet F: A population-based evaluation of the impact of antenatal screening for Down's syndrome in France, 1981-2004. BJOG 2004; 111: 485-490.

5 Irving C, Basu A, Richmond S, Burn J, Wren C: Twenty-year trends in prevalence and survival of Down syndrome. Eur J Hum Genet 2008; 16: 1336-1340.

6 Melve KK, Lie RT, Skjaerven R et al: Registration of Down syndrome in the Medical Birth Registry of Norway: validity and time trends. Acta Obstet Gynecol Scand 2008 87: 824-830.

7 Cocchi G, Gualdi S, Bower C et al: International trends of Down syndrome 1993-2004: births in relation to maternal age and terminations of pregnancies. Birth Defects Res Part A Clin Mol Teratol 2010; 88: 474-479.

8 Boyd PA, DeVigan C, Khoshnood B, Loane M, Garne E, Dolk H. The EUROCAT working group. Survey of prenatal screening policies in Europe for structural malformations and chromosome anomalies, and their impact on detection and termination rates for Neural Tube Defects and Down's syndrome. BJOG 2008; 115: 689-696.

9 Morris JK, Alberman E: Trends in Down's syndrome live births and antenatal diagnoses in England and Wales from 1989 to 2008: analysis of data from the National Down Syndrome Cytogenetic Register. BMJ 2010; 339: b3794.

10 Dolk H, Loane M, Garne E et al: Trends and geographic inequalities in the livebirth prevalence of Down Syndrome in Europe, 1980-1999. Revue Epidem Sante Publique 2005; 53: 2S87-2S95.

11 Pierannunzio D, Giorgi P: A decomposition model to evaluate evolution and factors of birth prevalence of Down syndrome in Europe. Genus 2005; 61: 85-118.

12 Boyd PA, Hauesler M, Barisic I, Loane M, Garne E, Dolk H: The EUROCAT Network: organisation and processes. Birth Defects Research Part A Clin Mol Teratol 2011; 91 S2-S15

13 Greenlees R, Neville A, Addor MC et al: EUROCAT member registries: organization and activities. Birth Defects Research Part A Clin Mol Teratol 2011; 91: S51-S100.

14 EUROCAT member registries. http://www.eurocat-network.eu/fullmembers.

15 Loane M, Dolk H, Garne E, Greenlees R and a EUROCAT Working Group. EUROCAT Data quality indicators for population-based registers of congenital anomalies. Birth Defects Research Part A Clin Mol Teratol 2011; 91: S23-S30.

16 Baird PA, Sadovnick AD: Maternal age-specific rates for Down syndrome: changes over time. Am J Med Genet 1988; 29: 917-927.

17 Morris JK, Savva GM: The risk of fetal loss following a prenatal diagnosis of Trisomy 13 or Trisomy 18. Am J Med Genet 2008; 146A: 827-832.

18 Irving C, Richmond S, Wren C, Longster C, Embleton ND: Changes in fetal prevalence and outcome for trisomies 13 and 18: a population-based study over 23 years. J Matern Fetal Neonatal Med 2011; 24: 137-141.

19 EUROCAT prevalence tables. http://www.eurocat-network.eu/accessprevalencedata/ prevalencetables.

20 Bishop J, Huether CA, Torfs C, Lorey F, Deddens J: Epidemiologic study of Down Syndrome in a racially diverse California population, 1989-1991. Am J Epidemiol 1997; 145: 134-147

21 Hook EB, Mutton DE, Idle R, Alberman E, Bobrow M: The natural history of Down syndrome conceptuses diagnosed prenatally that are not electively terminated. $\mathrm{Am} \mathrm{J}$ Hum Genet 1995; 57: 875-881.

22 Bray I, Wright DE, Davies C, Hook EB: Joint estimation of Down syndrome risk and ascertainment rates: a meta-analysis of nine published data sets. Prenat Diagn 1998 18: 9-20.

23 Hook EB: Chromosome abnormalities and spontaneous fetal death following amniocentesis: further data and associations with maternal age. Am J Med Genet 1983; 35 : 110-116.

24 Parker SE, Mai CT, Canfield MA et al: Updated national birth prevalence estimates for selected birth defects in the United States, 2004-2006. Birth Defects Research Part A Clin Mol Teratol 2010; 88: 1008-1016.

25 Savva GM, Walker K, Morris JK: The maternal age-specific live birth prevalence of trisomies 13 and 18 compared to trisomy 21 (Down syndrome). Prenat Diagn 2010; 30: $57-64$

26 Vendola C, Canfield M, Daiger SP et al: Survival of Texas infants born with Trisomies 21, 18 and 13. Am J Med Genet Part A Clin Mol Teratol 2010; 152A: 360-366.

27 Crider KS, Olney RS, Cragan JD: Trisomies 13 and 18: Population prevalences, characteristics, and prenatal diagnosis, Metropolitan Atlanta, 1994-2003. Am J Med Genet A 2008; 146A: 820-826.

28 EUROCAT 2010. Special Report: Prenatal Screening Policies in Europe 2010, EUROCAT Central Registry, University of Ulster. http://www.eurocat-network.eu/ content/Special-Report-Prenatal-Screening-Policies.pdf.

29 Savva GM, Morris JK, Mutton DE, Alberman E: Maternal age-specific fetal loss in Down syndrome pregnancies. Prenat Diagn 2006; 26: 499-504. 


\section{APPENDIX}

Fetal Survival Correction Factors ${ }^{\mathrm{a}}$ - Probability of surviving up to 20 weeks gestational age applied to each TOPFA case by trisomy

Gestation (weeks)

$\begin{array}{lllllllllll}10 & 11 & 12 & 13 & 14 & 15 & 16 & 17 & 18 & 19 & 20\end{array}$

$\begin{array}{llllllllllll}\text { Trisomy } 21 & 0.89 & 0.91 & 0.92 & 0.93 & 0.97 & 0.97 & 0.98 & 0.98 & 0.99 & 1.00 & 1.00\end{array}$

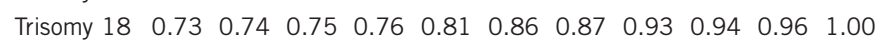

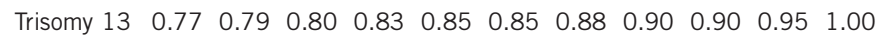

${ }^{a}$ Based on publications by Savva et $a^{29}$ and Morris and Savva ${ }^{17}$. Savva et $a^{R 9}$ analyzed fetal loss in 5177 PD pregnancies with trisomy 21 according to gestational age. Data from the survival curve in Figure 1 in the paper (personal communication) provided the probability of loss at each gestational age. Similarly, Morris and Savva ${ }^{17}$ analyzed fetal loss in 198 PD pregnancies with trisomy 13 and 538 pregnancies with trisomy 18 according to gestational pregnancies with trisomy 13 and 538 pregnancies with trisomy 18 according to gestational
age. Data from the survival curves in Figure 1 in the paper provided the probabilities of loss of pregnancies with trisomy 13 and 18 at each gestational age from 12 weeks of gestational age. Estimates for the fetal losses from 10 and 11 weeks gestational age were obtained by assuming the same fetal loss rates as observed in Down syndrome.
The risk of fetal loss before 20 weeks gestation given the pregnancy was terminated at $\mathrm{X}$ weeks gestation is estimated by the probability of fetal loss at X weeks divided by the probability of fetal loss at 20 weeks gestation. This risk is the survival correction weight given in Table 1 . These weights are then used to adjust the number of terminations reported at each gestational age to predict the number that would have survived to 20 weeks gestation. 